\title{
Can cholinium chloride form eutectic solvents with organic chloride-based salts?
}

\author{
Dinis O. Abranches a , Liliana P. Silva a , Mónia A.R. Martins ${ }^{\text {a, b, c }}{ }^{\text {, Luis Fernandez }}{ }^{\text {d }}$, \\ Simão P. Pinho ${ }^{\text {b, c }}$, João A.P. Coutinho ${ }^{\text {a, * }}$ \\ ${ }^{a}$ CICECO - Aveiro Institute of Materials, Department of Chemistry, University of Aveiro, 3810-193, Aveiro, Portugal \\ b Associate Laboratory LSRE-LCM, Instituto Politécnico de Bragança, Campus de Santa Apolónia, 5300-253, Bragança, Portugal \\ c Centro de Investigação de Montanha (CIMO), Instituto Politécnico de Bragança, Campus de Santa Apolónia, 5300-253, Bragança, Portugal \\ d Laboratorio de Termodinamica y Fisicoquímica de Fluidos, Universidad de Las Palmas de Gran Canaria, 35071, Parque Científico-Tecnológico, Canary \\ Islands, Spain
}

\section{A R T I C L E I N F O}

\section{Article history:}

Received 11 February 2019

Received in revised form

15 April 2019

Accepted 16 April 2019

Available online 20 April 2019

\section{Keywords:}

Cholinium chloride

Ionic liquids

Ionic liquid mixtures

Eutectic solvents

Solid-liquid equilibria

\begin{abstract}
A B S T R A C T
The high melting point of a large number of organic salts with potential ionic liquid-like properties, hinders their applicability as solvents. Considering the success of cholinium chloride on lowering the melting temperature of several substances and its success on forming deep eutectic solvents, this work studies its mixing with organic chlorides to lower their melting points producing eutectic ionic liquids.

The solid-liquid phase diagrams for binary mixtures composed of cholinium chloride and ten organic halides were experimentally measured. Surprisingly, cholinium chloride presented, for all these systems, significant positive deviations from ideal liquid behaviour that restricted its ability to lower the melting points of these mixtures. Only for mixtures with ammonium chloride, tetramethylammonium chloride, bis(2-hydroxyethyl)dimethylammonium chloride or cholinium bromide was cholinium chloride able to significantly lower the melting point of the mixture, but without reaching values close to room temperature $(298 \mathrm{~K})$. For a better understanding of the results obtained, the solid-liquid phase diagrams of four alkylammonium chloride-based mixtures were experimentally assessed and used to show that these compounds are better than cholinium chloride at inducing negative deviations from ideality, leading to greater melting point depressions.
\end{abstract}

(C) 2019 Elsevier B.V. All rights reserved.

\section{Introduction}

During the last decades, the study of ionic liquids attained a high degree of maturity [1-10]. They present an immense potential for tunability due to their ionic nature. Since they are composed of a cation and an anion, a judicious choice of their combination may help to design a compound with a set of desired properties. Nevertheless, in some cases, the relatively high melting point of the resulting compound may hinder its applicability, especially as a solvent to be used at or near room temperature (298 K).

Recently there has been a growing interest for ionic liquid mixtures [11,12]. Not only does the use of mixtures of ionic liquids increases their designer capability, it also allows for the reduction of the melting point of some ionic solids, allowing the preparation of

\footnotetext{
* Corresponding author.

E-mail address: jcoutinho@ua.pt (J.A.P. Coutinho).
}

eutectic ionic liquids from ionic solids. This concept was clearly addressed by Maximo et al. [13] showing that the melting point of hexafluorophosphate-based salts could be successfully lowered by preparing binary mixtures of them, and yet it has been explored only by few authors [14-18].

Cholinium chloride is an ionic solid commonly used in the preparation of deep eutectic solvents [19-21] since it not only forms biodegradable mixtures [22], but also acts as a hydrogen bond acceptor with a low melting enthalpy $(4.3 \mathrm{~kJ} / \mathrm{mol})$ [23], which contributes to substantial melting-point depression of its mixtures. As such, in this work, the feasibility of using cholinium chloride to lower the melting point of organic chlorides, with a melting point too high to be useful as a solvent, is explored.

When organic salts with a common ion are mixed, the resulting system is usually of the eutectic type, in some cases inducing the formation of intermediate compounds that may originate peritectic points. The common-ion specification is necessary to ensure that only the original salts may crystallize from the liquid mixture. If 
instead of 3 ions, a mixture of 4 ions is considered, the phase diagram becomes much more complex, with at least 4 different solid compounds precipitating from solution depending on the relative concentration of the ions present and the temperature of the system. For this reason, in this work only chloride-based salts are used, with the single exception of cholinium bromide that is used to evaluate the effect of a common cation upon the phase behaviour of cholinium chloride.

The eutectic-type solid-liquid equilibrium phase diagram of a mixture between two common-ion salts, when no solid-phase transitions are present, may be computed by describing each individual component melting curve using the following equation [24]:

$\ln \left(x_{i} \cdot \gamma_{i}\right)=\frac{\Delta_{m} h_{i}}{R} \cdot\left(\frac{1}{T_{m, i}}-\frac{1}{T}\right)+\frac{\Delta_{m} C p_{i}}{R} \cdot\left(\frac{T_{m, i}}{T}-\ln \frac{T_{m, i}}{T}-1\right)$

where $x_{i}$ is the mole fraction of the general salt $i, \gamma_{i}$ its activity coefficient, $\Delta_{m} h_{i}$ its melting enthalpy, $T_{m, i}$ its melting temperature and $\Delta_{m} C p_{i}$ its heat capacity change upon melting, while $R$ is the ideal gas constant and $T$ is the absolute temperature of the system. Equation (1) is not practical to use since the heat capacity change upon melting is not simple to measure and is not readily available in the literature. However, this term can, for most substances, be neglected in comparison with the other terms of the equation [24,25], leading to:

$\ln \left(x_{i} \cdot \gamma_{i}\right)=\frac{\Delta_{m} h_{i}}{R} \cdot\left(\frac{1}{T_{m, i}}-\frac{1}{T}\right)$

Equation (2) may be used to estimate the activity coefficients from the experimental phase diagrams. Moreover, to evaluate the non ideality of the liquid phase, the experimental results can also be compared with the prediction of Equation (2) when setting the activity coefficient value to 1 . In this work the solid-liquid phase diagrams of mixtures of cholinium chloride with ten organic chloride salts are measured and their non ideality discussed.

\section{Experimental}

\subsection{Chemicals}

The ionic solids used in this work and their abbreviations, along with their source and purity, are reported in Table 1 , while their structures are depicted in Fig. 1. Previous to being used, all salts were thoroughly dried under vacuum ( $0.1 \mathrm{~Pa})$, at room temperature $(298 \mathrm{~K})$ and constant stirring, for at least $72 \mathrm{~h}$. Their water content was measured using a Metrohm 831 Karl Fischer coulometer, with the analyte Hydranal Coulomat AG from Riedel-de-Haën and found to be lower than $600 \mathrm{ppm}$ in all instances.

\subsection{Phase diagrams measurement}

Binary mixtures of the ionic solids were prepared for the entire composition range of each system inside a dry-argon glove-box, by weighting the amounts of each pure substance using an analytical balance (model ALS 220-4 N from Kern) with an accuracy of $\pm 0.002 \mathrm{~g}$. After being molten and recrystallized, each mixture was crushed in a mortar inside a dry-argon glove-box and part of the powder was transferred to a glass capillary. Its melting point was measured using the melting point device model M-565 from Buchi, with a temperature resolution of $0.1 \mathrm{~K}$, as previously described [22], and a temperature gradient of $0.1 \mathrm{~K} \mathrm{~min}^{-1}$. This procedure was repeated at least three times and the measurements have an estimated reproducibility better than $2 \mathrm{~K}$.

In a few cases, a mixture with a paste-like consistency was obtained after the initial melting and recrystallization. In those cases, a visual method with an oil bath, described elsewhere [22], was employed instead. The mixtures were gradually heated until complete melting and the temperature was controlled with a Pt100 probe possessing a precision of $\pm 0.1 \mathrm{~K}$, which was previously calibrated against a calibrated platinum resistance thermometer, SPRT100 (Fluke-Hart Scientific 1529Chub-E4), traceable to the National Institute of Standards and Technology (NIST). This procedure was also repeated at least three times, presenting the same reproducibility as before (better than $2 \mathrm{~K}$ ).

The melting temperatures and enthalpies of $[\mathrm{MeCh}] \mathrm{Cl}$ and $\left[\mathrm{C}_{4} \mathrm{py}\right] \mathrm{Cl}$ were measured using differential scanning calorimetry (DSC) in a Hitachi DSC7000X model working at atmospheric pressure. Samples of approximately $2-5 \mathrm{mg}$ tightly sealed in aluminium pans were prepared inside the dry-argon glove-box and submitted to 3 repeated cooling-heating cycles at $5 \mathrm{Kmin}^{-1}$ (cooling) and $2 \mathrm{~K} \mathrm{~min}^{-1}$ (heating). The thermal transition temperatures were taken as the peak temperature. The equipment was calibrated with several standards (heptane, octane, decane, 4nitrotoluene, naphthalene, benzoic acid, diphenylacetic acid, indium, tin, caffeine, lead, zinc, potassium nitrate, water and anthracene) with weight fraction purities higher than 99\%. Due to the degradation upon melting, it was not possible to measure the melting properties of $\left[\mathrm{N}_{\mathrm{Bz}, 1,1,1}\right] \mathrm{Cl},\left[\mathrm{N}_{1,1,2 \mathrm{OH}, 2 \mathrm{OH}}\right] \mathrm{Cl},\left[\mathrm{C}_{3} \mathrm{C}_{1}\right.$ pip $] \mathrm{Cl}$, $\left[\mathrm{NH}_{4}\right]$ $\mathrm{Cl}$ and $\mathrm{ChBr}$.

Table 1

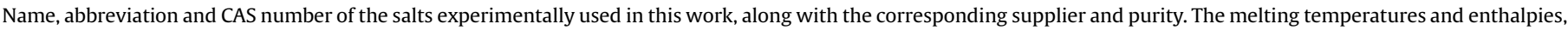
when available, are also included.

\begin{tabular}{|c|c|c|c|c|c|c|}
\hline Name & Abbreviation & CAS Number & Supplier & Purity (\%) & $T_{m} / \mathrm{K}$ & $\Delta h / \mathrm{kJ} / \mathrm{mol}$ \\
\hline Cholinium Chloride & $\mathrm{ChCl}$ & $67-48-1$ & Acros Organics & 98 & $597[23]$ & $4.3[23]$ \\
\hline beta-Methylcholine Chloride & {$[\mathrm{MeCh}] \mathrm{Cl}$} & $2382-43-6$ & $\mathrm{TCI}$ & $>98$ & $442.0^{\mathrm{a}}$ & $6.72^{\mathrm{a}}$ \\
\hline Tetramethylammonium Chloride & {$\left[\mathrm{N}_{1,1,1,1}\right] \mathrm{Cl}$} & $75-57-0$ & Sigma-Aldrich & 97 & $614.7^{\mathrm{b}}$ & 20.49 [12] \\
\hline Tetraethylammonium Chloride & {$\left[\mathrm{N}_{2,2,2,2}\right] \mathrm{Cl}$} & $56-34-8$ & Alfa Aesar & 98 & $535.4^{\mathrm{b}}$ & $51.24[12]$ \\
\hline Tetrapropylammonium Chloride & {$\left[\mathrm{N}_{3,3,3,3}\right] \mathrm{Cl}$} & $5810-42-4$ & Sigma-Aldrich & 98 & $502.4^{\mathrm{b}}$ & $66.58[12]$ \\
\hline Benzyltrimethylammonium Chloride & {$\left[\mathrm{N}_{\mathrm{Bz}, 1,1,1}\right] \mathrm{Cl}$} & $56-93-9$ & Acros Organics & 98 & $509.2^{\mathrm{b}}$ & - \\
\hline Bis(2-hydroxyethyl)dimethylammonium Chloride & {$\left[\mathrm{N}_{1,1,2 \mathrm{OH}, 2 \mathrm{OH}}\right] \mathrm{Cl}$} & $38402-02-7$ & Acros Organics & 99 & $563.7^{\mathrm{b}}$ & - \\
\hline 1-Methyl-1-Propylpiperidinium Chloride & {$\left[\mathrm{C}_{3} \mathrm{C}_{1}\right.$ pip $] \mathrm{Cl}$} & $1383436-85-8$ & Iolitec & 99 & $498.4^{\mathrm{b}}$ & $\longrightarrow$ \\
\hline Ammonium Chloride & {$\left[\mathrm{NH}_{4}\right] \mathrm{Cl}$} & $12125-02-9$ & JMGS & 99.5 & $632.2^{c}$ & $10.38^{\mathrm{c}}$ \\
\hline 1-Butylpyridinium Chloride & {$\left[\mathrm{C}_{4} \mathrm{py}\right] \mathrm{Cl}$} & $1124-64-7$ & Iolitec & 98 & $405.4^{\mathrm{a}}$ & $26.13^{\mathrm{a}}$ \\
\hline Cholinium Bromide & $\mathrm{ChBr}$ & $1927-06-6$ & $\mathrm{TCI}$ & 98 & $581.6^{\mathrm{b}}$ & $\longrightarrow$ \\
\hline
\end{tabular}

a) Measured in this work through DSC.

b) Measured in this work through the capillary-visual method.

c) Estimated in this work using experimental SLE data (see Supporting Information). 
<smiles>[1H][NH3+]</smiles><smiles>C[N+](C)(C)C</smiles>

$\left[\mathrm{NH}_{4}\right]^{+}$

$\left[\mathrm{N}_{1,1,1,1}\right]^{+}$<smiles>CC[N+](CC)(CC)CC</smiles>

$\left[\mathrm{N}_{2,2,2,2}\right]^{+}$<smiles>CCC[N+](CCC)(CCC)CCC</smiles>

$\left[\mathrm{N}_{3,3,3,3}\right]^{+}$<smiles>C[N+](C)(C)Cc1ccccc1</smiles>

$\left[\mathrm{N}_{\mathrm{Bz}, 1,1,1}\right]^{+}$<smiles>CCC[N+]1(C)CCCCC1</smiles>

$\left[\mathrm{C}_{3} \mathrm{C}_{1} \text { pip }\right]^{+}$<smiles>C[N+](C)(C)CCO</smiles>

$\mathrm{Ch}^{+}$<smiles>CC(O)C[N+](C)(C)C</smiles>

[MeCh]<smiles>C[N+](C)(CCO)CCO</smiles>

$\left[\mathrm{N}_{1,1,2 \mathrm{OH}, 2 \mathrm{OH}]}\right.$<smiles>CCCC[n+]1ccccc1</smiles>

$\left[\mathrm{C}_{4} \text { py }\right]^{+}$

Fig. 1. Chemical structure of the cations composing the ionic solid investigated in this work. Each abbreviation matches that used in Table 1 .

\section{Results}

The alkylammonium-based systems are herein first analysed (the experimental data is given in Tables $\mathrm{S} 1-\mathrm{S} 3$, as Supporting Information). Fig. 2 presents the experimental solid-liquid
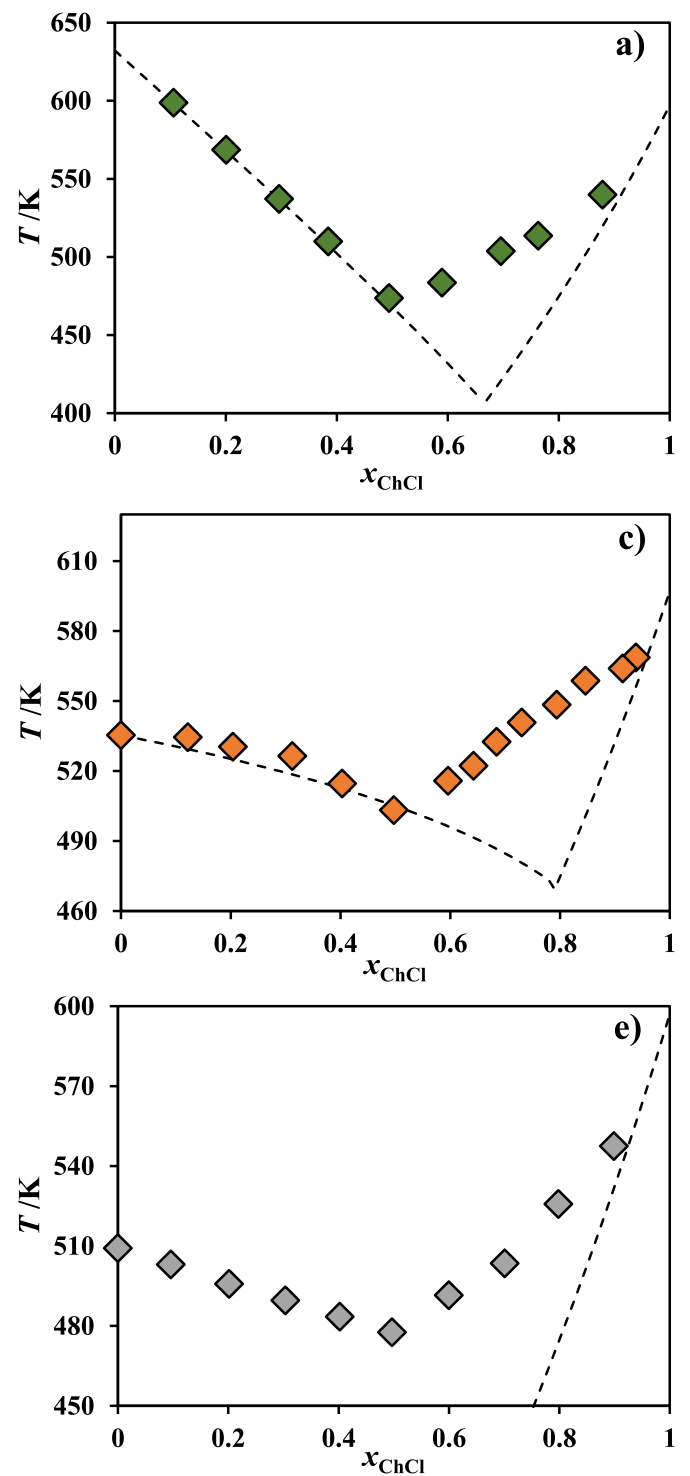

equilibrium (SLE) data along with the ideal liquid mixture phase diagram calculated by setting $\gamma_{i}$ equal to 1 in Equation (2) and using the fusion properties reported in Table 1.

It was not possible to calculate the complete ideal liquid mixture SLE curves for the systems with components $\left[\mathrm{N}_{\mathrm{Bz}, 1,1,1}\right] \mathrm{Cl}$ and
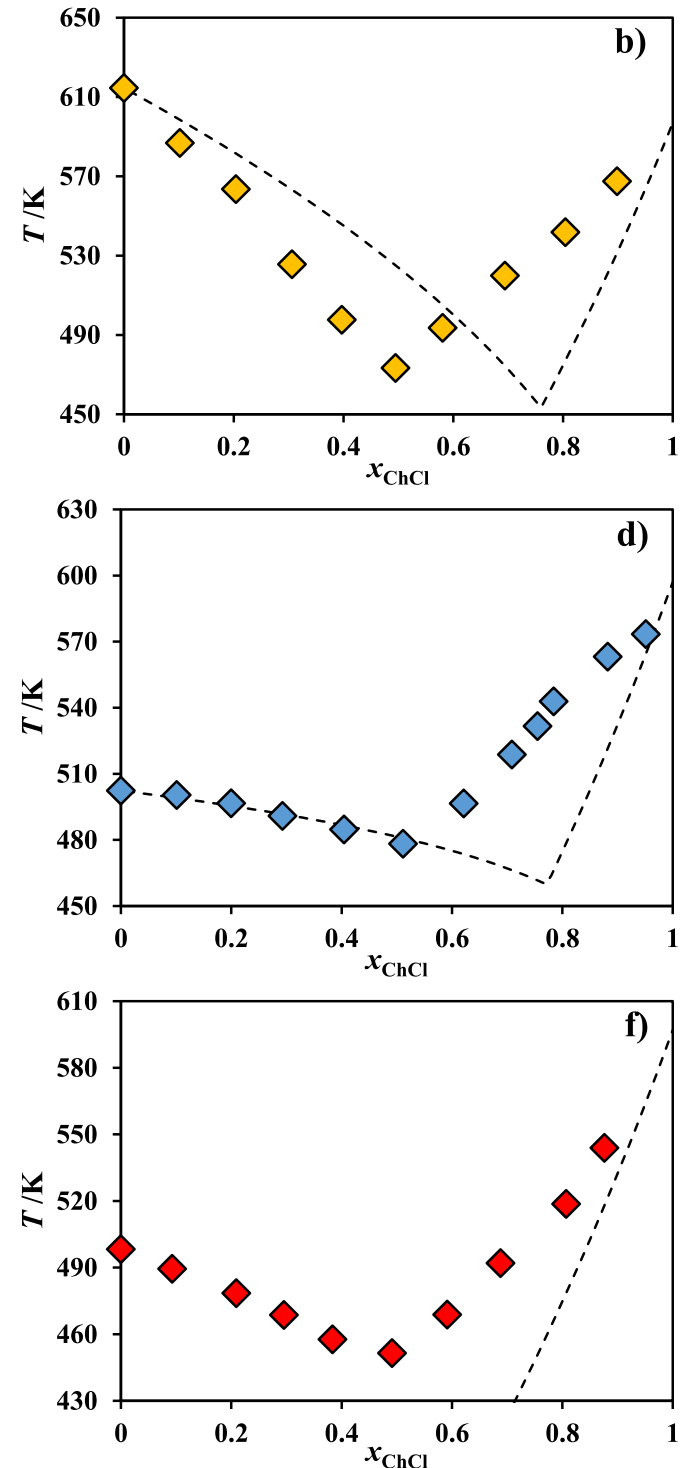

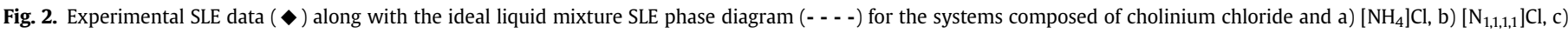
$\left.\left.\left[\mathrm{N}_{2,2,2,2}\right] \mathrm{Cl}, \mathrm{d}\right)\left[\mathrm{N}_{3,3,3,3}\right] \mathrm{Cl}, \mathrm{e}\right)\left[\mathrm{N}_{\mathrm{Bz}, 1,1,1}\right] \mathrm{Cl}$ and f) $\left[\mathrm{C}_{3} \mathrm{C}_{1}\right.$ pip $] \mathrm{Cl}$ 
$\left[C_{3} C_{1}\right.$ pip $] C l$ since their melting enthalpies are not available as these compounds decompose before melting. The $\left[\mathrm{NH}_{4}\right] \mathrm{Cl}$ ideal curve was calculated using melting properties estimated in this work from experimental SLE data (see section S2 of the supporting information). Except for $\left[\mathrm{N}_{1,1,1,1}\right] \mathrm{Cl}$, no significant melting-point depressions were observed upon mixing the ionic solids with cholinium chloride.

The most striking feature of these results is that, unlike observed for the phase diagrams of cholinium chloride-based (deep) eutectic systems published in the literature [26-28], for which the cholinium chloride melting curves present a near ideal behaviour, or a small negative deviation to ideality, here, for all systems studied, positive deviations from ideality are observed. However, there is no evident relationship between the magnitude of these deviations and the chemical structure of the second component of the mixture. The experimental activity coefficients reported in Fig. 3 show very similar values and behaviour for all systems studied.

Another interesting feature to note in Fig. 3, and in Fig. 2b as well, is the negative deviation from ideality presented by $\left[\mathrm{N}_{1,1,1,1}\right] \mathrm{Cl}$, in contrast with the near ideal behaviour of $\left[\mathrm{NH}_{4}\right] \mathrm{Cl},\left[\mathrm{N}_{2,2,2,2}\right] \mathrm{Cl}$ and $\left[\mathrm{N}_{3,3,3,3}\right] \mathrm{Cl}$. The ionic liquid $\left[\mathrm{N}_{4,4,4,4}\right] \mathrm{Cl}$ was also previously shown to behave ideally when mixed with choline chloride [23]. The explanation for the behaviour of $\left[\mathrm{N}_{1,1,1,1}\right] \mathrm{Cl}$ is not yet clear. Since it cannot form hydrogen bonding nor any other specific interaction with $\mathrm{ChCl}$, entropic effects may be the cause for its strong negative deviations from ideality.

To aid in explaining the phenomenon introduced in the last paragraph and to investigate the role of cholinium chloride's hydroxyethyl group on the deviations from ideality reported in Fig. 3, ChCl was replaced with $\left[\mathrm{N}_{1,1,1,1}\right] \mathrm{Cl}$. Note that $\mathrm{ChCl}$ and $\left[\mathrm{N}_{1,1,1,1}\right]$ $\mathrm{Cl}$ are structurally very similar (Fig. 1 ), the difference being that one of the latter methyl groups is replaced by a hydroxyethyl group in the former. The new SLE phase diagrams were experimentally assessed and are shown in Fig. 4.

While cholinium chloride revealed positive deviations from ideality in all systems, as shown in Figs. 2 and 3, $\left[\mathrm{N}_{1,1,1,1}\right] \mathrm{Cl}$ reveals negative deviations from ideality, similar to what was shown in Fig. 2b, or a near-ideal behaviour. This suggests that the hydroxyethyl group present in cholinium chloride allows for stronger interactions in the pure substance, either in the form of $\mathrm{OH}-\mathrm{Cl}$ interactions between cation and anion, as suggested by Hammond et al. [29] et al., or in the form of hydrogen bonding between cations $(\mathrm{OH}-\mathrm{OH})$, as recently proposed by Knorr et al. [30] et al. and

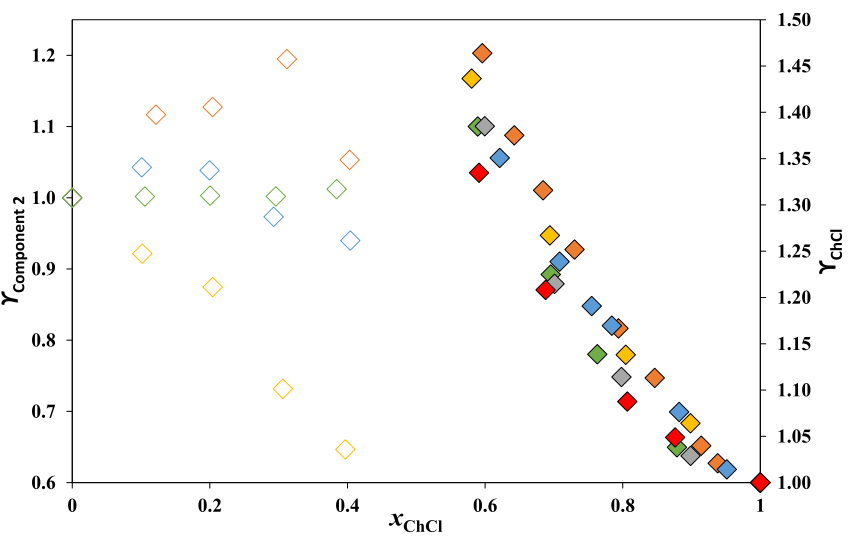

Fig. 3. Experimental activity coefficients for cholinium chloride (full marker, right axis) and the second component (empty marker, left axis) in the binary mixtures herein studied $\left(\mathrm{ChCl}+\mathrm{NH}_{4} \mathrm{Cl}, \diamond,\left[\mathrm{N}_{1,1,1,1}\right] \mathrm{Cl}, \diamond,\left[\mathrm{N}_{2,2,2,2}\right] \mathrm{Cl}, \diamond,\left[\mathrm{N}_{3,3,3,3}\right] \mathrm{Cl}, \diamond,\left[\mathrm{N}_{\mathrm{Bz}, 1,1,1}\right] \mathrm{Cl}\right.$,, and $\left[\mathrm{C}_{3} \mathrm{C}_{1}\right.$ pip $\left.] \mathrm{Cl}, \diamond\right)$, calculated using the experimental data presented in Table $\mathrm{S} 1$ and the melting properties included in Table 1.
Gilmore et al. [31] et al. This explains cholinium chloride positive deviations from ideality, while the cations in the alkylammoniumbased ionic solids cannot participate in hydrogen bonding nor offer any other type of specific interactions. Particularly, the $\left[\mathrm{N}_{1,1,1,1}\right] \mathrm{Cl}$ salt used in the four systems above has no centres capable of specific interactions other than coulombic.

Bearing in mind the objective of lowering the melting point of ionic solids, mixtures $\left[\mathrm{N}_{1,1,1,1}\right] \mathrm{Cl} /\left[\mathrm{N}_{2,2,2,2}\right] \mathrm{Cl}$ (Fig. 4 b) and $\left[\mathrm{N}_{1,1,1,1}\right] \mathrm{Cl} /$ $\left[\mathrm{N}_{3,3,3,3}\right] \mathrm{Cl}$ (Fig. $4 \mathrm{c}$ ) are remarkable. The strong negative deviations from ideality revealed by all components in these mixtures leads to a eutectic temperature of around $175 \mathrm{~K}$ in the first case, about $60 \mathrm{~K}$ below the ideal eutectic temperature, and $88 \mathrm{~K}$ in the second case, about $130 \mathrm{~K}$ below the ideal eutectic temperature, making of this a true eutectic ionic liquid. This suggests that the use of quaternary alkyl ammonium chlorides may be a better approach to produce eutectic ionic liquids, by decreasing the eutectic temperature well below the melting temperature of the pure constituents, than the cholinium chloride used in this work. This approach will be object of a future work.

Alternatively to the alkylammonium chlorides, $\mathrm{ChCl}$ was also combined with $[\mathrm{MeCh}] \mathrm{Cl},\left[\mathrm{N}_{1,1,2 \mathrm{OH}, 2 \mathrm{OH}}\right] \mathrm{Cl},[\mathrm{C} 4 \mathrm{py}] \mathrm{Cl}$ or $\mathrm{ChBr}$. The experimental SLE phase diagrams for these binary systems are displayed in Fig. 5, along with the calculated ideal liquid mixture SLE curves, whenever the melting properties of the pure components are available. The positive deviations from ideality of cholinium chloride, albeit less severe, are analogous to those reported in the previous section for alkylammonium-based salts. Nevertheless, cholinium chloride was able to successfully lower the melting point

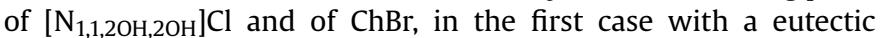
temperature close to $435 \mathrm{~K}$.

The eutectic mixtures of cholinium chloride with quaternarium ammonium or ionic-liquid analogues of high melting points, unlike other eutectic ionic liquids based on mixtures with a common anion previously studied [14-18], show important deviations to ideality. In particular, the hydroxyl group of cholinium chloride seems to induce specific interactions between these cations and a strong interaction with the anion that induce strong positive deviations to ideality in most mixtures. This is clearly shown in the study of the four binary systems formed by $\left[\mathrm{N}_{1,1,1,1}\right] \mathrm{Cl}$, where removing the hydroxyl group induces strong negative deviations, on analogous binary mixtures, evidencing the role of the hydroxyl group on the cholinium interactions. But not only the nature of the hydrogen bonding between hydroxyl groups seems to matter as the $\mathrm{ChBr}-\mathrm{ChCl}$ system also presents positive deviations that seem to be induced by the different nature of the cation-anion interactions in the two compounds. The results here reported reinforce the idea that the ability of the cholinium chloride to induce the formation of low melting point eutectic mixtures is probably more connected to its low melting enthalpy than to the formation of donor:acceptor hydrogen bonding complexes commonly accepted. In particular, the results from this work suggest that cholinium chloride is not the best choice to prepare eutectic ionic liquids, by mixing it with other organic salts, but instead tetra-alkyl ammonium chlorides show an interesting potential for that purpose, that will be explored in a future work.

\section{Conclusions}

In this work, the feasibility of using cholinium chloride to lower the melting point of ionic substances, unfit for the definition of ionic liquid, was studied. The SLE phase diagrams of ten cholinium chloride-based mixtures were experimentally measured and are herein reported and discussed. Although cholinium chloride presented positive deviations from ideality in all systems investigated, its small melting enthalpy alleviated this problem and led to useful 

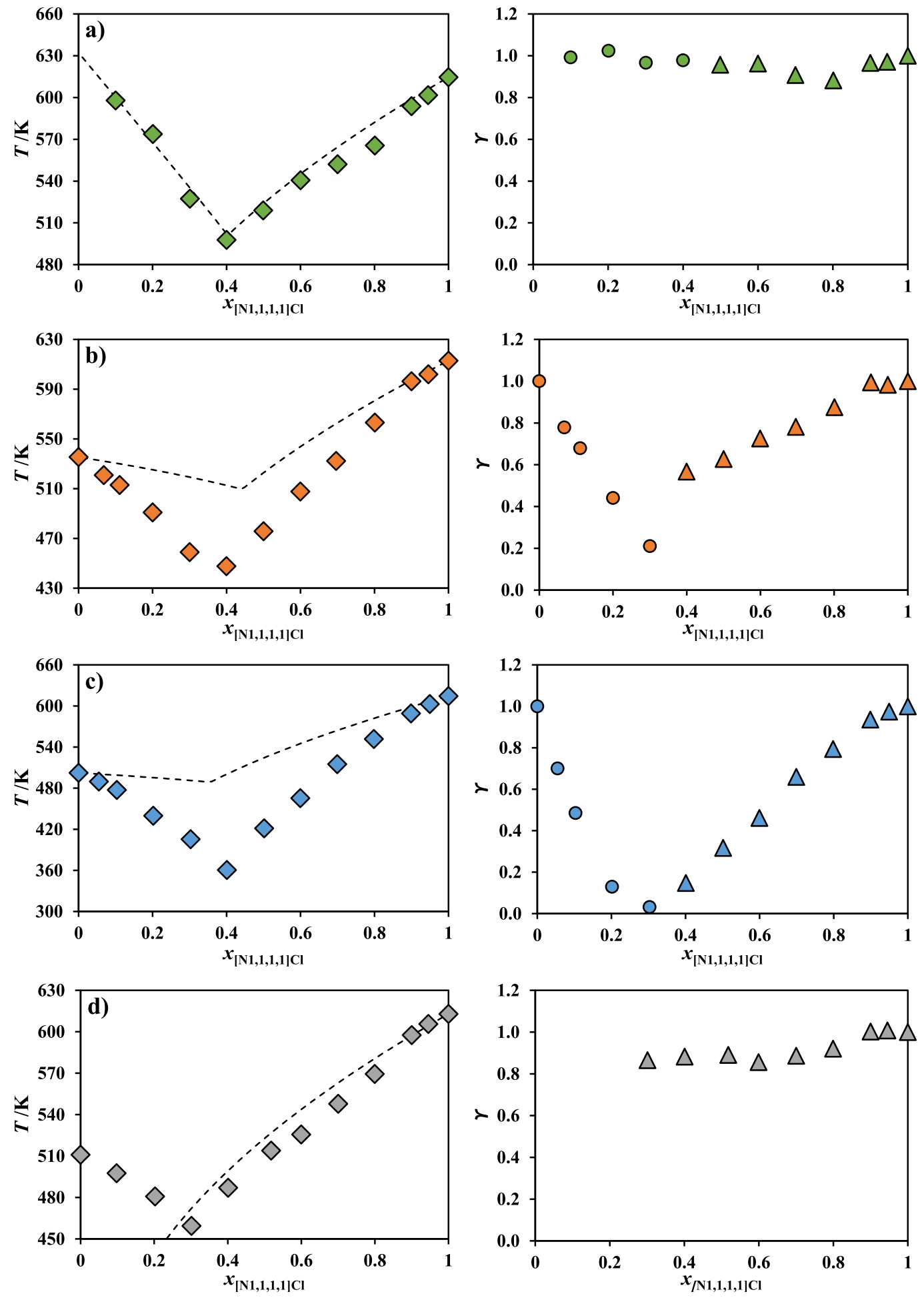

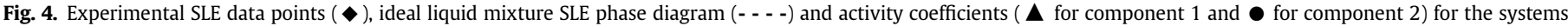
composed of $\left[\mathrm{N}_{1,1,1,1}\right] \mathrm{Cl}$ and a) $\left[\mathrm{NH}_{4}\right] \mathrm{Cl}$, b) $\left.\left[\mathrm{N}_{2,2,2,2}\right] \mathrm{Cl}, \mathrm{c}\right)\left[\mathrm{N}_{3,3,3,3}\right] \mathrm{Cl}$ and d) $\left[\mathrm{N}_{\mathrm{Bz}, 1,1,1}\right] \mathrm{Cl}$.

melting point depressions in four substances: cholinium bromide, ammonium chloride, tetramethylammonium chloride and bis(2hydroxyethyl)dimethylammonium chloride.

To better understand the thermodynamic behaviour of mixtures of cholinium chloride and alkylammonium-based ionic salts, $\mathrm{ChCl}$ was replaced with $\left[\mathrm{N}_{1,1,1,1}\right] \mathrm{Cl}$ and the SLE phase diagram measurements were repeated. The replacement of the hydroxyethyl group of the cholinium cation by a methyl group in $\left[\mathrm{N}_{1,1,1,1}\right] \mathrm{Cl}$ led to negative deviations from the ideal behaviour. These results suggest that the cholinium chloride hydroxyethyl group plays a significant role on its interactions with other cholinium chloride pairs, and seem to be the basis of its positive deviations from ideality when mixed with alkylammonium-based ionic solids.

This study also showed that the mixtures $\left[\mathrm{N}_{1,1,1,1}\right] \mathrm{Cl} /\left[\mathrm{N}_{2,2,2,2}\right] \mathrm{Cl}$ 

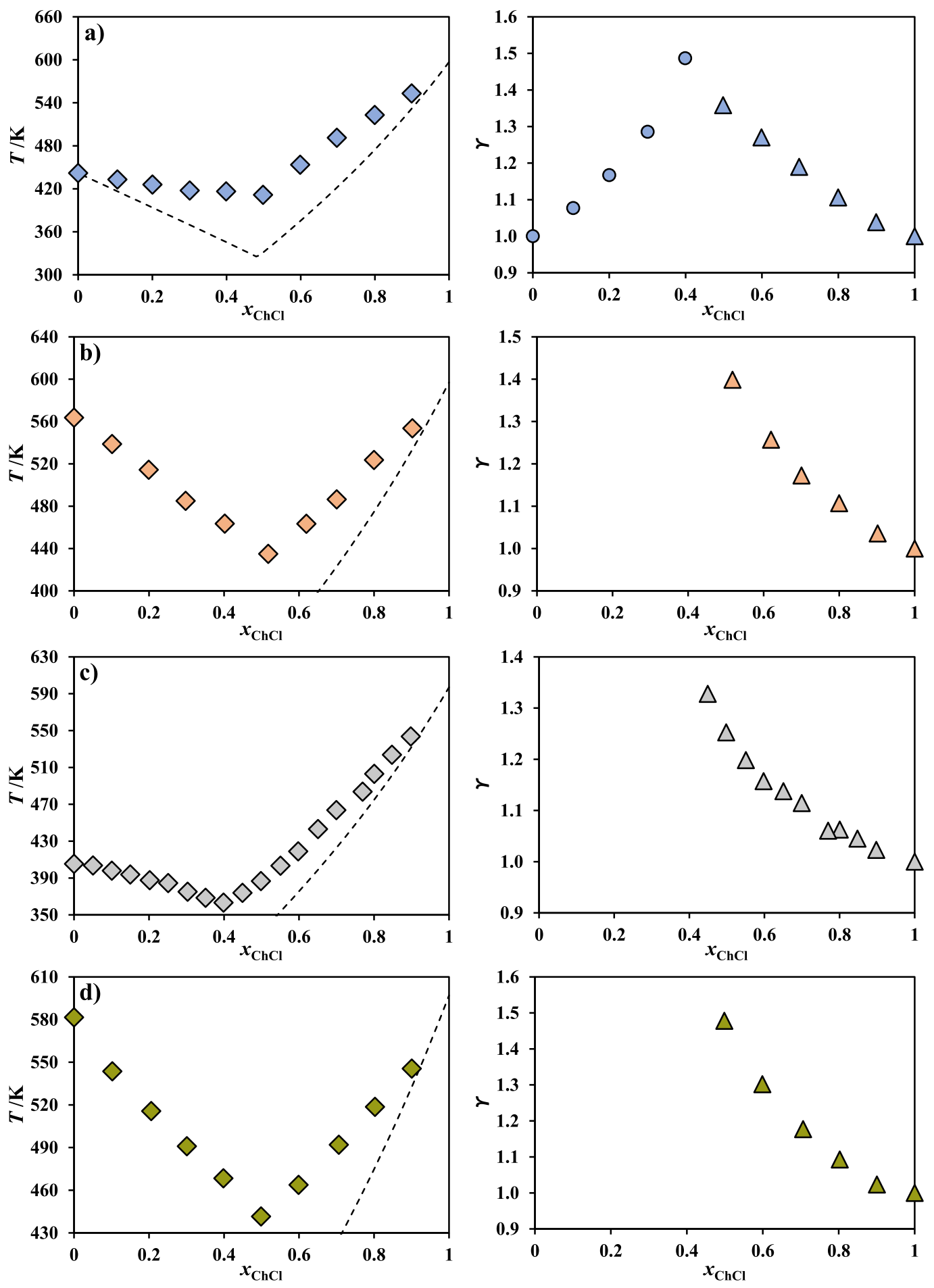

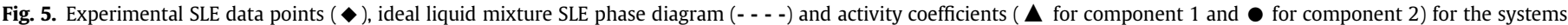
composed of cholinium chloride and a) $[\mathrm{MeCh}] \mathrm{Cl}$, b) $\left.\left[\mathrm{N}_{1,1,2 \mathrm{OH}, 2 \mathrm{OH}}\right] \mathrm{Cl}, \mathrm{c}\right)\left[\mathrm{C}_{4} \mathrm{py}\right] \mathrm{Cl}$ and d) $\mathrm{ChBr}$.

and $\left[\mathrm{N}_{1,1,1,1}\right] \mathrm{Cl} /\left[\mathrm{N}_{3,3,3,3}\right] \mathrm{Cl}$ presented large negative deviations from ideality, leading to remarkable melting point depressions. The eutectic temperature of the mixture $\left[\mathrm{N}_{1,1,1,1}\right] \mathrm{Cl} /\left[\mathrm{N}_{3,3,3,3}\right] \mathrm{Cl}$ is around $360 \mathrm{~K}, 140 \mathrm{~K}$ below the melting point of $\left[\mathrm{N}_{3,3,3,3}\right] \mathrm{Cl}$ and $250 \mathrm{~K}$ below the melting point of $\left[\mathrm{N}_{1,1,1,1}\right] \mathrm{Cl}$. This suggests that tetralkyl ammonium chlorides may be better at producing eutectic ionic liquids and should prompt further investigation on the nature of these mixtures.

\section{Acknowledgments}

This work was developed in the scope of the project CICECO Aveiro Institute of Materials, POCI-01-0145-FEDER-007679 (Ref. FCT UID/CTM/50011/2013) and Associate Laboratory LSRELCM, POCI-01-0145-FEDER-006984 (Ref. FCT UID/EQU/50020/ 2019), and project MultiBiorefinery (POCI-01-0145-FEDER016403), all financed by national funds through the FCT/MCTES 
(PIDDAC) and when appropriate co-financed by FEDER under the PT2020 Partnership Agreement. FCT is also acknowledged for funding the project DeepBiorefinery (PTDC/AGRTEC/1191/2014). The authors acknowledge the European Research Council under the European Union's Seventh Framework Programme (FP7/ 2007-2013)/ERC grant agreement no. 337753. M.A.R.M. acknowledges financial support from NORTE-01-0145-FEDER-000006 funded by NORTE2020 through PT2020 and ERDF. L.P.S. acknowledges FCT for her PhD grant (SFRH/BD/135976/2018).

\section{Appendix A. Supplementary data}

Supplementary data to this article can be found online at https://doi.org/10.1016/j.fluid.2019.04.019.

\section{References}

[1] J.G. Huddleston, H.D. Willauer, R.P. Swatloski, A.E. Visser, R.D. Rogers, Room temperature ionic liquids as novel media for "clean" liquid-liquid extraction, Chem. Commun. (1998) 1765-1766, https://doi.org/10.1039/A803999B.

[2] T. Welton, Room-temperature ionic liquids. Solvents for synthesis and catalysis, Chem. Rev. 99 (1999) 2071-2084, https://doi.org/10.1021/cr980032t.

[3] M. Freemantle, An Introduction to Ionic Liquids: RSC, Royal Society of Chemistry, 2010

[4] F. Endres, S. Zein El Abedin, Air and water stable ionic liquids in physical chemistry, Phys. Chem. Chem. Phys. 8 (2006) 2101, https://doi.org/10.1039/ b600519p.

[5] J.S. Wilkes, A short history of ionic liquids-from molten salts to neoteric solvents, Green Chem. 4 (2002) 73-80, https://doi.org/10.1039/b110838g.

[6] J.F. Brennecke, E.J. Maginn, Ionic liquids: innovative fluids for chemical processing, AIChE J. 47 (2001) 2384-2389, https://doi.org/10.1002/ aic.690471102.

[7] T.P. Thuy Pham, C.-W. Cho, Y.-S. Yun, Environmental fate and toxicity of ionic liquids: a review, Water Res. 44 (2010) 352-372, https://doi.org/10.1016/ j.watres.2009.09.030.

[8] S. Aparicio, M. Atilhan, F. Karadas, Thermophysical properties of pure ionic liquids: review of present situation, Ind. Eng. Chem. Res. 49 (2010) 9580-9595, https://doi.org/10.1021/ie101441s.

[9] K. Marsh, J. Boxall, R. Lichtenthaler, Room temperature ionic liquids and their mixtures-a review, Fluid Phase Equilib. 219 (2004) 93-98, https://doi.org/ 10.1016/j.fluid.2004.02.003.

[10] R.D. Rogers, K.R. Seddon, Ionic liquids-solvents of the future? Science 302 (2003) 792-793.

[11] H. Niedermeyer, J.P. Hallett, I.J. Villar-Garcia, P.A. Hunt, T. Welton, Mixtures of ionic liquids, Chem. Soc. Rev. 41 (2012) 7780, https://doi.org/10.1039/ c2cs35177c.

[12] P.V.A. Pontes, E.A. Crespo, M.A.R. Martins, L.P. Silva, C.M.S.S. Neves, G.J. Maximo, M.D. Hubinger, E.A.C. Batista, S.P. Pinho, J.A.P. Coutinho, G. Sadowski, C. Held, Measurement and PC-SAFT modeling of solid-liquid equilibrium of deep eutectic solvents of quaternary ammonium chlorides and carboxylic acids, Fluid Phase Equilib. 448 (2017) 69-80, https://doi.org/ 10.1016/j.fluid.2017.04.007.

[13] G.J. Maximo, R.J.B.N. Santos, P. Brandão, J.M.S.S. Esperança, M.C. Costa, A.J.A. Meirelles, M.G. Freire, J.A.P. Coutinho, Generating ionic liquids from ionic solids: an investigation of the melting behavior of binary mixtures of ionic liquids, Cryst. Growth Des. 14 (2014) 4270-4277, https://doi.org/ $10.1021 / \mathrm{cg} 500655 \mathrm{~s}$

[14] M. Mirarabrazi, O. Stolarska, M. Smiglak, C. Robelin, Solid-liquid equilibria for a pyrrolidinium-based common-cation ternary ionic liquid system, and for a pyridinium-based ternary reciprocal ionic liquid system: an experimental study and a thermodynamic model, Phys. Chem. Chem. Phys. 20 (2018) 637-657, https://doi.org/10.1039/C7CP04678B.

[15] A.R.R. Teles, H. Correia, G.J. Maximo, L.P.N. Rebelo, M.G. Freire, A.B. Pereiro, J.A.P. Coutinho, Solid-liquid equilibria of binary mixtures of fluorinated ionic liquids, Phys. Chem. Chem. Phys. 18 (2016) 25741-25750, https://doi.org 10.1039/C6CP05372F.

[16] O. Stolarska, A. Soto, H. Rodríguez, M. Smiglak, Thermal behaviour of mixtures of 1-alkylpyridinium halides with and without a common ion, J. Mol. Liq. 268 (2018) 781-790, https://doi.org/10.1016/j.molliq.2018.07.106.

[17] A.A.C. Toledo Hijo, G.J. Maximo, R.L. Cunha, F.H.S. Fonseca, L.P. Cardoso, J.F.B. Pereira, M.C. Costa, E.A.C. Batista, A.J.A. Meirelles, Phase equilibrium and physical properties of biobased ionic liquid mixtures, Phys. Chem. Chem. Phys. 20 (2018) 6469-6479, https://doi.org/10.1039/C7CP06841G.

[18] A.S. Ivanova, T. Brinzer, E.A. Roth, V.A. Kusuma, J.D. Watkins, X. Zhou, D. Luebke, D. Hopkinson, N.R. Washburn, S. Garrett-Roe, H.B. Nulwala Eutectic ionic liquid mixtures and their effect on CO 2 solubility and conductivity, RSC Adv. 5 (2015) 51407-51412, https://doi.org/10.1039/ C5RA06561E.

[19] Q. Zhang, K. De Oliveira Vigier, S. Royer, F. Jérôme, Deep eutectic solvents: syntheses, properties and applications, Chem. Soc. Rev. 41 (2012) 7108 https://doi.org/10.1039/c2cs35178a.

[20] E.L. Smith, A.P. Abbott, K.S. Ryder, Deep eutectic solvents (DESs) and their applications, Chem. Rev. 114 (2014) 11060-11082, https://doi.org/10.1021/ cr300162p.

[21] A.P. Abbott, D. Boothby, G. Capper, D.L. Davies, R.K. Rasheed, Deep eutectic solvents formed between choline chloride and carboxylic acids: versatile alternatives to ionic liquids, J. Am. Chem. Soc. 126 (2004) 9142-9147, https:// doi.org/10.1021/ja048266j.

[22] K. Radošević, M. Cvjetko Bubalo, V. Gaurina Srček, D. Grgas, T. Landeka Dragičević, I. Radojčić Redovniković, Evaluation of toxicity and biodegradability of choline chloride based deep eutectic solvents, Ecotoxicol. Environ. Saf. 112 (2015) 46-53, https://doi.org/10.1016/j.ecoenv.2014.09.034.

[23] L. Fernandez, L.P. Silva, M.A.R. Martins, O. Ferreira, J. Ortega, S.P. Pinho, J.A.P. Coutinho, Indirect assessment of the fusion properties of choline chloride from solid-liquid equilibria data, Fluid Phase Equilib. 448 (2017) 9-14, https://doi.org/10.1016/j.fluid.2017.03.015.

[24] J. Rowlinson, Molecular thermodynamics of fluid-phase equilibria, J. Chem Thermodyn. 2 (1970) 158-159, https://doi.org/10.1016/0021-9614(70) 90078-9.

[25] J.A.P. Coutinho, S.I. Andersen, E.H. Stenby, Evaluation of activity coefficient models in prediction of alkane solid-liquid equilibria, Fluid Phase Equilib. 103 (1995) 23-39, https://doi.org/10.1016/0378-3812(94)02600-6.

[26] E.A. Crespo, L.P. Silva, M.A.R. Martins, L. Fernandez, J. Ortega, O. Ferreira G. Sadowski, C. Held, S.P. Pinho, J.A.P. Coutinho, Characterization and modeling of the liquid phase of deep eutectic solvents based on fatty acids/ alcohols and choline chloride, Ind. Eng. Chem. Res. 56 (2017) 12192-12202, https://doi.org/10.1021/acs.iecr.7b02382.

[27] M.A.R. Martins, S.P. Pinho, J.A.P. Coutinho, Insights into the nature of eutectic and deep eutectic mixtures, J. Solut. Chem. (2018), https://doi.org/10.1007/ s10953-018-0793-1.

[28] D.O. Abranches, M. Larriba, L.P. Silva, M. Melle-Franco, J.F. Palomar, S.P. Pinho, J.A.P. Coutinho, Using COSMO-RS to Design Choline Chloride Pharmaceutical Eutectic Solvents, 2019. Submitted to Fluid Phase Equilib.

[29] O.S. Hammond, D.T. Bowron, K.J. Edler, Liquid structure of the choline chloride-urea deep eutectic solvent (reline) from neutron diffraction and atomistic modelling, Green Chem. 18 (2016) 2736-2744, https://doi.org/ 10.1039/C5GC02914G.

[30] A. Knorr, K. Fumino, A.-M. Bonsa, R. Ludwig, Spectroscopic evidence of "jumping and pecking" of cholinium and H-bond enhanced cation-cation interaction in ionic liquids, Phys. Chem. Chem. Phys. 17 (2015) 30978-30982, https://doi.org/10.1039/C5CP03412D.

[31] M. Gilmore, L.M. Moura, A.H. Turner, M. Swadźba-Kwaśny, S.K. Callear, J.A. McCune, O.A. Scherman, J.D. Holbrey, A comparison of choline:urea and choline:oxalic acid deep eutectic solvents at 338 K, J. Chem. Phys. 148 (2018) 193823, https://doi.org/10.1063/1.5010246. 